\title{
Combating School Bullying through Developmental Guidance for Positive Youth Development and Promoting Harmonious School Culture
}

\author{
Eadaoin K. P. Hui, ${ }^{1}$ Sandra K. M. Tsang, ${ }^{2}$ and Bella C. M. Law ${ }^{2}$ \\ ${ }^{1}$ Division of Learning Development and Diversity, Faculty of Education, \\ The University of Hong Kong, Hong Kong \\ ${ }^{2}$ Department of Social Work and Social Administration, Faculty of Social Sciences, \\ The University of Hong Kong, Hong Kong \\ Received 30 November 2010; Revised 29 March 2011; Accepted 15 August 2011 \\ Academic Editor: Joav Merrick
}

Bullying and violence, which can bring detrimental effects, are situations which young people have to face in their process of development. Though school bullying has been a spreading and explicit problem in Hong Kong schools, most of the programs or guidelines dealing with the problem lack citywide, recognized initiatives and the effectiveness of these programs is unknown due to the lack of evaluation. The present paper discusses preventing school bullying from a developmental guidance perspective, using the positive youth development paradigm and promoting the values of harmony and forgiveness at the whole-school level to cultivate a harmonious school culture as a way of combating school bullying.

KEYWORDS: Bullying, forgiveness, harmonious school culture, developmental guidance, positive youth development, whole-school approach 


\section{INTRODUCTION}

School bullying has become a spreading and explicit problem in Hong Kong schools and is an issue of growing concern for parents, teachers, and educators [1,2]. Following the definition of Olweus [3], bullying refers to intentional, oppressive behavior against another person that causes physical and/or psychological harm. It is an abusive behavior which is typically repeated over time; that is, such behavior is not a one-time occurrence. Bullying behaviors are usually classified into one of four categories: (1) physical bullying refers to overt physical aggression such as hitting, pushing, kicking, spitting, and punching; (2) verbal bullying refers to overt verbal aggression such as name-calling, teasing, insulting and threatening speech; (3) social exclusion behaviors aim to hurt the victims by damaging their peer relationships or social standing. Such behaviors include ignoring the presence of the victims, spreading hurtful rumors, excluding the victims from a friendship group, or threatening others not to play with the victims; (4) extortion includes asking for money or others' property $[4,5]$. Often, a real or perceived imbalance of power persists between the bullies and the victims $[3,6]$. For example, the child bullies who are older have greater physical strength and are more socially or verbally adept than the victims. Also, bullies are more psychologically manipulative or have a higher social standing than the targeted victims $[5,7]$.

Research studies have shown that school bullying has detrimental effects on victims and the bullies themselves as well as on bystanders, which affect their academic, social, emotional, mental, and psychological functioning as well as physical health. Problems arising from bullying may persist into adulthood $[6,8,9]$. Factors such as students' psychosocial functioning and their accessibility to violent values are found to be related to school bullying $[4,6,10,11]$. Students, who have unstable emotions, unsatisfactory school performance, poor relationships with their family members, teachers, and peers, are more likely to be involved in peer victimization [4]. Those who are exposed to violent values, such as growing up in an aggressive background [10,12], having frequent contact with deviant peers [13], and being exposed to violence messages through the media $[14,15]$, are more likely to engage in violence, either as bullies or as victims. Further, students lack skills and strategies to deal with incidents of bullying. Victims of bullying often develop intense anger and anxiety, and suffer low self-esteem or depression $[16,17]$. Some may misdirect their anger and in turn become bullies [2]. Hence, the way in which schools respond to school bullying is pertinent.

In school guidance, there have been three major approaches in dealing with student problems, including school bullying, namely, remedial, preventive, and developmental guidance [18]. Remedial guidance focuses on offering interventions and therapies to students experiencing emotional, psychological, or behavioral difficulties. In the case of school bullying, a remedial guidance approach focuses on the individual student level, victims as well as bullies. Such an approach is a responsive and curative approach. Preventive guidance is a proactive approach, which stresses anticipation of problems like bullying, enhancing students' awareness of bullying and victimization, and skills and strategies to handle bullying. Developmental guidance approach, on the other hand, is a positive approach to facilitate students' whole person development, including their personal, social, and moral self-formation. Developmental guidance addresses issues such as self-knowledge, self-responsibility, interpersonal relationships, and bonding. These are delivered through a guidance curriculum at classroom level and schoolwide programs. Through education on the need for respect for self and for others, tolerance of individual differences, self-determination and responsible decision making, students will attain positive self- and interpersonal development. Among these three approaches, developmental guidance contributes the most to the holistic development of students and is considered as one of the most effective measures in promoting students' healthy development and in preventing juvenile delinquency. Developmental guidance has been the guidance approach and focus of schools in Hong Kong and elsewhere [19].

School climate is another factor related to school bullying. Students are at a greater risk of engaging in bullying acts if in their school there are often conflicts or low morale among students and teachers. On the contrary, schools with a positive climate have less bullying-related problems, and students are more likely to engage in altruistic behavior $[10,20]$. These research findings point to the significance of promoting 
a harmonious school culture as a means of preventing school bullying. The present paper discusses preventing school bullying from a developmental guidance perspective, using the positive youth development paradigm and promoting the values of harmony and forgiveness at the whole-school level to cultivate a harmonious school culture as a way of combating school bullying.

\section{INTERVENTIONS TO COMBAT BULLYING}

School bullying is a systemic and a complex process of social interactions that involves bullies, victims, peers, adults, parents, and school as well as home environments [21]. A review of bullying intervention programs suggests that intervention may target at the individual student level, for example, teaching the victims self-assertion skills, helping the victims to deal with their negative emotions arising from being bullied, helping the bullies to develop empathy for the victims, and forming a support group involving the victims and the bystanders [22]. Such an approach is a remedial guidance approach in combating school bullying. Some interventions target at the classroom level, for example, through classroom discussion to enhance students' awareness of and developing rules to deal with bullying. Other interventions target at the whole-school level, such as devising a whole-school antibullying policy, that is, communicated to the wholeschool community [22]. Peer-led intervention utilizes peer support such as peer counseling to improve students' communication and empathy skills, and peer mediation to resolve conflicts. Other forms of peerled intervention involve setting up cooperative work groups, creating a circle of friends to support students at risk of victimization [23, 24]. Whole-school interventions usually target at all school members including staff, pupils, and parents to enhance their knowledge and responses to bullying [3]. Since bullying springs from factors external to individual child subsystems, bullying interventions need to involve different systems within the school community in order to have a significant consistent impact. A whole-school approach to bullying that is directed at the entire school context and involves a comprehensive, multilevel strategy that targets bullies, victims, bystanders, families, and community becomes pertinent [21, 25]. Classroom intervention and whole-school antibullying programs illustrate the preventive guidance approach to school bullying. These programs usually target at providing training in social skills, altering group norms, and increasing self-efficacy. A review of the effectiveness of antibullying interventions has shown that the incidence of bullying cannot be reduced by implementing the curriculum alone [21]. Implementation of intervention across schools has a higher success rate [5], and the intervention is most effective when the antibullying curriculum is integrated into the regular school curriculum [23]. School climate factors, such as interpersonal relationships and quality of communication, the important ecological factors influencing bullying, however, are not usually included in the whole-school intervention program [26]. Developmental guidance precisely addresses to building a positive school climate and a guidance-oriented community where each individual's rights are respected and valued.

The spreading and explicit problem of bullying in Hong Kong schools is illustrated in a study of local secondary schools, which found that over half of the respondents were involved in bullying [1]. In another study, it was found that nearly 90 per cent of the respondents witnessed verbal bullying in the past half year and nearly 70 per cent of the respondents experienced physical bullying in the same period [4]. In another study on cyber bullying, 22 per cent of the respondents bullied others, 30 per cent of the respondents were being bullied, and nearly 60 per cent witnessed cyber-bullying in the past one year [27]. However, it was not until recently that some programs or guidelines dealing with the problem of school bullying were developed by the governmental authorities and the local practitioners [17, 28-32]. Nevertheless, most of the programs lack citywide, recognized initiatives [1], and the effectiveness of these programs is unknown due to a lack of evaluation. Antibullying intervention has focused on the individual student level, adopting a suppressive strategy. Such an approach is bully focused and blame driven. Measures such as withdrawal of privileges, meeting parents, school suspension, and expulsion have been adopted by schools to deter students from bullying. However, this strategy is considered punitive and may worsen the bully-victim relationship or even intensify the problem $[1,23]$. Such an approach is also very remedial and reactive in focus, falling 
short of teaching bullies and victims' skills for dealing with conflicts. Another approach is a comprehensive antibullying strategy which aims to tackle risk factors contributing to bullying and to involve all people in the whole school [1]. Four useful tactics underlying this strategy are: (1) encouraging victims to tell the truth and develop a strong character; (2) educating bullies who lack social skills; (3) shaming bullies who intend to do harm, or who have done harm, in a reintegrative manner; (4) promoting a peaceful environment by using restorative practices [1, page 546]. Such an approach focuses on prevention of the problem and functions more like preventive guidance in schools. There has been insufficient integration of antibullying initiatives into schools' policy from a developmental guidance perspective as a means of strengthening students' personal and social development. There has also been a lack of intervention at the classroom level, such as incorporating an antibullying curriculum into the school's regular guidance curriculum, and a similar lack of intervention at the whole-school level through promoting a harmonious school culture. A guidance curriculum which focuses on developing students' strengths and the values of harmony and forgiveness will help address the problem of bullying from a developmental guidance perspective.

\section{TACKLING BULLYING FROM A POSITIVE YOUTH DEVELOPMENT PERSPECTIVE}

Positive youth development (PYD) focuses on developing adolescents' strengths and competencies, personal character, social connections, and the ability to care and contribute to society through a planned curriculum and program [33]. Developing adolescents' assets and strengths is important [34]. It is asserted that the achievement of the above developmental tasks will increase adolescent psychosocial well-being and societal well-being. The goals of PYD are very similar to those of developmental guidance, for both are positive approaches to facilitate the whole-person development of young people via a systematic and planned school guidance curriculum [18]. Both PYD and developmental guidance stress the importance of focusing on strength and on developing competence. Such a positive approach, which is not "problem driven", is particularly relevant in combating problems like bullying in schools.

Catalano et al. [35] identified fifteen psychological constructs or competencies as the key elements of the successful positive youth development programs. Constructs which promote interpersonal relationships, such as bonding, recognizing positive behavior, fostering prosocial involvement and prosocial norms, and those which promote emotional, moral, social, and behavioral competence contribute to building strengths in adolescents which will serve to counteract bullying and other forms of school violence.

To promote the holistic development of adolescents in Hong Kong schools, the "P.A.T.H.S. to Adulthood, a Jockey Club Youth Enhancement Scheme" has adopted the positive youth development paradigm and devised a curriculum incorporating the fifteen psychological constructs. The Tier 1 program of Project P.A.T.H.S., a universal positive youth development program, functions as a developmental guidance curriculum for all students. Issues that adolescents may face, such as sexuality, concepts of money and success, bullying, internet addiction, and substance and drug abuse, are incorporated as examples and illustrations in the program, with an attempt to promote students' psychosocial competencies [36]. The evaluation findings consistently show that Project P.A.T.H.S. is effective in promoting positive youth development [37-42]. Specifically, positive effects in reducing adolescent delinquent behavior among the junior secondary years have been found [43].

The newly devised P.A.T.H.S. units which address to bullying share functions similar to a classroombased intervention. As shown in Table 1, these units aim to enhance students' understanding and awareness of the nature of bullying and cyber bullying, the needs of the bullies and the victims, the role of the bystanders in bullying, the moral responsibility in stopping bullying, the respect of others, and cyber ethics. As a PYD program, these units foster specifically the psychological constructs of bonding, resilience, social competence, emotional competence, behavioral competence, moral competence, and prosocial norms. Since these units are taught as a classroom curriculum for all students in their respective class levels, the students will acquire competence, positive skills, and strategies in facing bullying and school violence. Hence, these PYD units also tackle bullying from a developmental guidance perspective through a systematic curriculum targeting at all students. 
TABLE 1: An overview on the foci of the P.A.T.H.S. units on bullying.

\begin{tabular}{|c|c|c|}
\hline Level & Goals & Constructs \\
\hline Secondary 1 & $\begin{array}{l}\text { (1) To understand what is meant by bullying and its } \\
\text { consequences, to avoid being a bully or a victim } \\
\text { (2) To understand the true needs of the bullies and identify } \\
\text { proper approaches to minimise bullying } \\
\text { (3) To learn what should be done in the face of bullying }\end{array}$ & $\begin{array}{l}\text { Emotional competence, } \\
\text { Behavioral competence, } \\
\text { Social competence, } \\
\text { Resilience }\end{array}$ \\
\hline Secondary 2 & $\begin{array}{l}\text { (1) To understand that bystanders play an important role in } \\
\text { bullying } \\
\text { (2) To learn to be a wise and responsible bystander }\end{array}$ & $\begin{array}{l}\text { Moral competence, } \\
\text { Behavioral competence, } \\
\text { Prosocial norms }\end{array}$ \\
\hline Secondary 3 & $\begin{array}{l}\text { (1) To learn to be a responsible bystander in cyber bullying } \\
\text { (2) To learn and practice the motto "seek common ground and } \\
\text { respect differences; seek harmony but not uniformity" }\end{array}$ & $\begin{array}{l}\text { Moral competence, } \\
\text { Social competence }\end{array}$ \\
\hline
\end{tabular}

There are several merits in adopting the positive approach in tackling bullying. First, it addresses bullying from a positive youth development paradigm, stressing the importance of competency building. Issues relating to bullying are used as a context through which students learn appropriate social skills, emotional management skills, and the ability to understand others' emotions, to appreciate and forgive others. In addition, units target at helping students to explore proper attitudes and skills when facing unjust and violent situations, to learn to see things from other people's perspectives, and consider appropriate ways of responding. Through enhancing students' moral, social, and behavioral competence, the incidences of bullying can be prevented. Second, this is a deliberate attempt to incorporate antibullying elements in a form of classroom curriculum to be delivered in the schools' regular curriculum. Enhancing students' knowledge about bullying and positive ways of handling it through classroom discussion and activities is more effective as an intervention strategy [23]. Students can be equipped with knowledge and skills to foster a positive and culturally appropriate learning environment. Cooperative group work and activities which enhance students' intrapersonal and interpersonal skills can reduce the extent of victimization of vulnerable students and promote a peaceful, loving, and respectful classroom environment [4]. Third, building students' assets and strengths in interpersonal relationships, bonding, and competence will help build a caring school ethos, leading to a more harmonious school culture.

\section{TACKLING BULLYING THROUGH CULTIVATING A HARMONIOUS SCHOOL CULTURE}

Bullying behavior is influenced by the social context [44]. A positive school climate can reduce aggression and bullying as well as promote positive youth development $[22,25,45]$. In addition to the integration of an antibullying curriculum with a positive youth development program like Project P.A.T.H.S., as mentioned above, other strategies can be adopted to complement this approach in order to cultivate a caring school climate which values harmony, with zero tolerance towards violence.

\subsection{Fostering Forgiveness as a Value and Coping Strategy}

Forgiveness is a moral concept and a moral response to interpersonal conflicts and injustice. Forgiveness is defined as a replacement of negative sentiments with positive effect, thinking, and behavior towards the offender [46]. In forgiving, the offended becomes less motivated to do harm and more motivated to do positive things to benefit the offender [47]. Forgiveness is not excusing, condoning, or justifying the unjust offences. Rather, forgiveness is a strategy to reduce stress arising from the transgression and the unforgiving 
emotions. The victim may employ decisional forgiveness, that is, having the intention to give up revenge or avoidance towards the offender, and emotional forgiveness, which is replacing negative with positive emotions [48]. Forgiveness interventions have been used with adults and college students to deal with hurts and offences (see [49, 50]). Recently, forgiveness interventions following Enright's process model have been used with children and adolescents [51-54]. In Hong Kong, forgiveness has been introduced as a developmental guidance curriculum for adolescents [55] and as a small group preventive guidance intervention with children who judged themselves to have been hurt and chose not to forgive the offenders [56]. Both studies adopted Enright's process model and implemented forgiveness education as school guidance programs. The results indicated that those who received the forgiveness programs outperformed their counterparts in forgiveness attitude, conceptual understanding of forgiveness, and psychological wellbeing. Specifically, these students learnt empathy as a key strategy to forgive and indicated more readiness and confidence to apply forgiveness as a strategy in dealing with offences in future.

Ahmed and Braithwaite [57] suggest the link between forgiveness, reconciliation, and reducing bullying. The absence of forgiveness and reconciliation makes no contribution to building emotional scaffolding. Egan and Todorov [5] further suggest that forgiveness can be introduced as a strategy to help students respond to being bullied. Antibullying intervention with individual students may incorporate forgiveness as an element to help victims to deal with stress and negative emotions. This will have the benefit of deterring victims from turning into bullies. Klatt and Enright [58] suggest that forgiveness can be conceptualized from a positive youth development perspective for education. Forgiveness is not yet included as a psychological construct within the positive youth developmental paradigm, though Project P.A.T.H.S. does include a unit on forgiveness.

Introducing forgiveness as a developmental guidance curriculum has several benefits. First, conceptualizing forgiveness from a PYD perspective will contribute to fostering forgiveness as a strength and asset, not only for victims and those at risk of school violence but also for all students. Strategies such as empathy and reframing will benefit not only victims but also potential bullies and bystanders in their responses to offences and unjust situations. Forgiveness is a choice and a decision. Teaching young people forgiveness as a strategy in dealing with interpersonal conflict will increase their behavioral and emotional competence. Second, teaching forgiveness as a value and a coping strategy can help students to be less inclined to seek revenge and retaliation in interpersonal conflicts and to be more positive and proactive in seeking harmony. Hence, incorporating forgiveness as a guidance curriculum that targets the whole-school community will help promote a more caring, tolerant, and responsive school climate.

\subsection{Social Support of Teachers}

Social support has been found to be an important contextual factor in countering bullying, yet there is a lack of explicit application of social support in antibullying programs and interventions [59]. Research studies have demonstrated that students' perceived school satisfaction is related to supportive teacherstudent relationships [60], teacher support [61], and a caring and supportive school climate [62]. Teacher support has been found to be a protective factor against students' suicidal ideation [63], has acted as a significant predictor to students' perceived school satisfaction [64], and played a mediating role in the relationship between victimization and school maladjustment [59]. However, not all teachers perceive bullying as serious, know how to intervene and prevent bullying, or have the confidence to manage disruptive behavior [65]. This points to the importance of educating teachers about bullying and strengthening teachers as support in the school setting. A whole-school intervention program by Olweus [3] incorporated teachers to provide support on the whole-school level by, for example, identifying bullying incidents, providing increased supervision in secluded areas and coordinating with parents, school staff, and students. On the classroom level, teacher support includes establishing class rules against bullying, setting consequences for violating the rules. However, just setting rules or a one-off discussion in the classroom or on the wholeschool level is not sufficient. Involving teachers in delivering guidance programs addressing bullying has further benefits. Teachers may integrate antibullying themes within the school developmental guidance 
programs and values education programs, so that nonviolence and tolerance can be presented as a consistent message to all students and highlighted as the ethos of the school. Also, teachers act as a role model for students. Supportive teacher-student relationships will encourage students, whether victims or bystanders to seek help. Teachers may foster attitudes such as acceptance, respect, tolerance, and forgiveness and relate their importance to inter-personal relationships and social harmony. On the individual student level, teachers may offer support to bullies, victims, and the peers of bullies and victims, in dealing with bullying and conflicts. Involving teachers systematically on all three levels is a more comprehensive strategy to prevent bullying. As peer victimization is an important determinant leading to school dissatisfaction [66] and peer conflicts lower students' liking of their schools [67], on-going efforts and social support from teachers are pertinent to building a positive and caring classroom and school climate.

\subsection{Involving Peers as a Support}

Students value having a peer to listen to their experience of being bullied [24]. Peer-led antibullying interventions, such as peer counseling and peer mediation, have been found to have positive outcomes, which also lead to an improvement of the school climate [23]. Students, who used peer counseling for bullying service were identified as pertinent such characteristics as peer counselors having good listening skills, being trustworthy, maintaining confidentiality, and providing advice on solving bullying-related problems [68]. Peer counseling has been used increasingly in schools in Hong Kong and elsewhere as a form of peer support to facilitate junior students' adjustment and learning. Such support can be extended to include antibullying. In addition to training peer counselors' skills, such as active listening, empathy, and problem solving, the units which address school bullying in the Project P.A.T.H.S. can be incorporated in the training program to enhance peer counselors' knowledge and understanding of the nature of bullying, the feelings and emotions of the victims, the needs and mentalities of the bullies, and proper approaches to minimize bullying. However, the support of adults such as teachers and social workers is essential. Furthermore, support needs to go beyond peer counselors for bullying service to other peers in the school community, for not all students use peer counseling due to the fear of being stigmatized [68]. The Project P.A.T.H.S. includes units addressed specifically to the role of bystanders in bullying, factors affecting the attitudes, and responses of bystanders to bullying incidents. All students, whether victims, bullies, or bystanders will be taught explicitly in classroom guidance programs about bullying as a form of violence and its effects on the school community. Such an approach targeting all students will further enhance peers as a support system in the school community. Further, schoolwide developmental guidance programs educating students about respect for individual differences and the value of harmony, justice, and responsibility will help to build a more tolerant and caring school climate.

\subsection{Promoting Nonviolence and Harmony as a Whole-School Approach to Counter Bullying}

Research and practices in school guidance and pastoral care have affirmed the importance of having a wholeschool approach in facilitating students' whole-person development $[18,19,69]$. Under the framework of a whole-school approach, guidance and supports are provided to all students, not merely students who are at risk, and is a responsibility of all teachers, not only the guidance personnel and professionals. Guidance can be delivered at individual student level, classroom and whole-school levels. Developing a systematic and planned guidance curriculum, and integrating guidance themes into the school's formal and informal curriculum are essential elements under this framework. Such an approach also requires school to have a whole-school policy which details the goals, system of management, coordination, and communication among teachers, parents, and professionals. Promoting a whole-school approach to guidance is a way to 
cultivate a positive school ethos [18]. Hence, this approach is very much in line with promoting nonviolence and harmony as a positive way to combat school bullying.

Cultivating a harmonious school culture needs to be done as a whole-school approach, ranging from the individual student level, class level, to the schoolwide program level as discussed above. Such an endeavor needs to be further supported at the whole-school system level. First, a whole-school policy which stresses non-violence and tolerance needs to be integrated with the school's guidance policy, so that there will be consensus and consistency among all staff in their responses to the problems of bullying and peer victimization and the promotion of non-violence. Such a policy needs to be communicated to the students and parents. Second, in addition to cultivating the values of harmony and non-violence through school's values and moral education curriculum, the implementation of the PYD antibullying program at classroom level which fosters students' bonding, competencies, and self-determination will contribute to a more positive and caring class ethos. Further, the integration of themes such as respect, tolerance, forgiveness, and justice with academic subject teaching will help enhance effectiveness, for the teaching of values must be ongoing and integrated into the school curriculum so that the values can be kept front and center [23]. Third, on the management level, another essential element that needs to be dealt with from a whole-school system perspective is collaboration with professionals such as school psychologists, school counselors, and social workers in issues such as identifying students at risk of bullying and victimization and offering timely intervention. The implementation of Tier II program of Project P.A.T.H.S., for example, will require teachers and professionals to work in collaboration. Fourth, as mentioned above, teachers play a very important role in fostering values through classroom teaching, delivering classroom guidance programs such as the PYD antibullying programs, and forgiveness education. This will require school to plan and organize professional development programs to enhance teachers' knowledge and skills and to offer individual support. Involving peers as support and working with parents are other essential elements under the framework of a whole-school approach, which have been adopted in whole-school antibullying intervention. Lastly, the involvement of the entire school community, students, parents, teachers, administrators, professionals, and adjunct school staff in the practice and support of such a school policy is pertinent to building a safer, more caring, responsive, and harmonious school culture. [23]. Combating bullying as a whole-school approach to guidance is a matter of cultivating a guidanceoriented ethos, in which concern, love, and compassion are advocated as values for students' whole-person development.

\section{CONCLUSION}

Bullying and violence are situations which many young people have to face in their process of development, whether as bullies or victims or bystanders. A more proactive way to prevent bullying is to adopt a developmental guidance approach to strengthen young people's skills and competencies in inter-personal relationships and bonding. Programs, which, like Project P.A.T.H.S., adopt a positive youth development paradigm and implement it as a classroom developmental guidance curriculum are a proactive approach to counter bullying. Cultivating a school environment which cherishes forgiveness and harmony and endorses respect, non-violence, tolerance, and compassion is another important strategy. This will require a systematic approach to strengthen teachers and peers as social support and will involve the entire school community on the policy, management, and implementation levels to promote a caring school culture as a proactive way to tackle bullying.

\section{ACKNOWLEDGMENT}

The preparation for this paper and the Project P.A.T.H.S. were financially supported by The Hong Kong Jockey Club Charities Trust. 


\section{REFERENCES}

[1] D. S. W. Wong, "School bullying and tackling strategies in Hong Kong," International Journal of Offender Therapy and Comparative Criminology, vol. 48, no. 5, pp. 537-553, 2004.

[2] D. O. B. Lam and A. W. H. Liu, "The path through bullying-A process model from the inside story of bullies in Hong Kong secondary schools," Child and Adolescent Social Work Journal, vol. 24, no. 1, pp. 53-75, 2007.

[3] D. Olweus, Bullying at School: What We Know and What We Can Do, Basil Blackwell, Oxford, UK, 1993.

[4] D. S. W. Wong, D. P. P. Lok, T. Wing Lo, and S. K. Ma, "School bullying among Hong Kong Chinese primary school children," Youth and Society, vol. 40, no. 1, pp. 35-54, 2008.

[5] L. A. Egan and N. Todorov, "Forgiveness as a coping strategy to allow school students to deal with the effects of being bullied: theoretical and empirical discussion," Journal of Social and Clinical Psychology, vol. 28, no. 2, pp. 198-222, 2009.

[6] K. Rigby, Bullying in Schools and What to Do About It, ACER Press, Victoria, Australia, 2007.

[7] S. Bauman and C. Hurley, "Teachers' attitudes and beliefs about bullying," Journal of School Violence, vol. 4, no. 3, pp. 49-61, 2005.

[8] K. Rigby, "Consequences of bullying in schools," Canadian Journal of Psychiatry, vol. 48, no. 9, pp. 583-590, 2003.

[9] Y. Cheng, I. M. Newman, M. Qu et al., "Being bullied and psychosocial adjustment among middle school students in China," The Journal of School Health, vol. 80, no. 4, pp. 193-199, 2010.

[10] C. H. Lee, "An ecological systems approach to bullying behaviors among middle school students in the United States," Journal of Interpersonal Violence, vol. 26, no. 8, pp. 1664-1693, 2011.

[11] D. L. Espelage, M. K. Holt, and R. R. Henkel, "Examination of peer-group contextual effects on aggression during early adolescence," Child Development, vol. 74, no. 1, pp. 205-220, 2003.

[12] A. C. Baldry, "Bullying in schools and exposure to domestic violence," Child Abuse and Neglect, vol. 27, no. 7, pp. 713-732, 2003.

[13] D. L. Haynie, T. Nansel, P. Eitel et al., "Bullies, victims, and bully/victims: distinct groups of at-risk youth," Journal of Early Adolescence, vol. 21, no. 1, pp. 29-49, 2001.

[14] F. J. Zimmerman, G. M. Glew, D. A. Christakis, and W. Katon, "Early cognitive stimulation, emotional support, and television watching as predictors of subsequent bullying among grade-school children," Archives of Pediatrics and Adolescent Medicine, vol. 159, no. 4, pp. 384-388, 2005.

[15] E. Kuntsche, W. Pickett, M. Overpeck, W. Craig, W. Boyce, and M. G. de Matos, "Television viewing and forms of bullying among adolescents from eight countries," Journal of Adolescent Health, vol. 39, no. 6, pp. 908-915, 2006.

[16] J. W. Y. Ng and S. K. M. Tsang, "School bullying and the mental health of junior secondary school students in Hong Kong," Journal of School Violence, vol. 7, no. 2, pp. 3-20, 2008.

[17] A. L. C. Fung and J. L. P. Wong, Project C.A.R.E.: Children and Adolescents at Risk Education, Hong Kong Christian Service, Hong Kong, 2007.

[18] E. K. P. Hui, "Guiding students for positive development," in Learning and Development of Asian Students: What the 21 st Century Teachers Need to Think About, L. F. Zhang, J. Biggs, and D. Watkins, Eds., pp. 221-244, Pearson Education South Asia, Singapore, 2010.

[19] E. K. P. Hui, "Guidance as a whole school approach in Hong Kong: from remediation to student development," International Journal for the Advancement of Counselling, vol. 22, no. 1, pp. 69-82, 2000.

[20] D. J. James, M. Lawlor, P. Courtney, A. Flynn, B. Henry, and N. Murphy, "Bullying behaviour in secondary schools: what roles do teachers play?" Child Abuse Review, vol. 17, no. 3, pp. 160-173, 2008.

[21] R. C. Vreeman and A. E. Carroll, "A systematic review of school-based interventions to prevent bullying," Archives of Pediatrics and Adolescent Medicine, vol. 161, no. 1, pp. 78-88, 2007.

[22] P. K. Smith, K. Ananiadou, and H. Cowie, "Interventions to reduce school bullying," Canadian Journal of Psychiatry, vol. 48, no. 9, pp. 591-599, 2003.

[23] F. Mishna, "An overview of the evidence on bullying prevention and intervention programs," Brief Treatment and Crisis Intervention, vol. 8, no. 4, pp. 327-341, 2008.

[24] H. Cowie and R. Olafsson, "The role of peer support in helping the victims of bullying in a school with high levels of aggression," School Psychology International, vol. 21, no. 1, pp. 79-95, 2000. 
[25] K. S. Whitted and D. R. Dupper, "Best practices for preventing or reducing bullying in schools," Children and Schools, vol. 27, no. 3, pp. 167-175, 2005.

[26] J. D. Smith, B. H. Schneider, P. K. Smith, and K. Ananiadou, "The effectiveness of whole-school antibullying programs: a synthesis of evaluation research," School Psychology Review, vol. 33, no. 4, pp. 547-560, 2004.

[27] The Hong Kong Federation of Youth Groups, "A study on cyber bullying of secondary school students," Youth Study Series 44, 2010, http://yrc.hkfyg.org.hk/chi/ys44.html.

[28] D. S. W. Wong, S. K. S. Chiu, A. Y. T. Fung, and Y. Y. P. Li, Helping Pupils away from Bullying, Centre for Restoration of Human Relationships, Hong Kong, 2002.

[29] Guidance and Discipline Section, Education and Manpower Bureau, "Co-creating a harmonious school" resource package, 2003, http://peacecampus.edb.hkedcity.net/ .

[30] S. W. Wong, School Bullying and Responding Tactics: A Life Education Approach, Arcadia Press, Hong Kong, 2003.

[31] Guidance and Discipline Section, Education and Manpower Bureau, "Co-creating a harmonious school-stop bullying" web-based resource package, 2004, http://peace2.edb.hkedcity.net/index.htm.

[32] Centre for Restoration of Human Relationships, Building harmonious campuses in Hong Kong, http://www.restoration.com.hk/service1_a.html.

[33] B. J. Gomez and P. M. M. Ang, "Promoting positive youth development in schools," Theory into Practice, vol. 46, no. 2, pp. 97-104, 2007.

[34] K. J. Pittman, M. Irby, J. Tolman, N. Yohalem, and T. Ferber, "Preventing problems, promoting development, encouraging engagement: competing priorities or inseparable goals?" The Forum for Youth Investment, 2003, http://forumfyi.org/node/105.

[35] R. F. Catalano, M. L. Berglund, J. A. Ryan, H. S. Lonczak, and J. D. Hawkins, "Positive youth development in the United States: research findings on evaluations of positive youth development programs," 1998, http://aspe.hhs.gov/hsp/PositiveYouthDev99/index.htm\#toc.

[36] D. T. L. Shek, H. K. Ma, and R. C. F. Sun, "Development of a new curriculum in a positive youth development program: the Project P.A.T.H.S. in Hong Kong," TheScientificWorldJOURNAL. In press.

[37] D. T. L. Shek, H. K. Ma, R. C. F. Sun, and D. W. M. Lung, "Process evaluation of the Tier 1 program (Secondary 1 curriculum) of the Project P.A.T.H.S.: findings based on the full implementation phase," TheScientificWorldJOURNAL: TSW Holistic Health \& Medicine, vol. 8, pp. 35-46, 2008.

[38] D. T. L. Shek and R. C. F. Sun, "Evaluation of Project P.A.T.H.S. (Secondary 1 Program) by the program participants: Findings based on the Full Implementation Phase," Adolescence, vol. 43, no. 172, pp. 807-822, 2008.

[39] D. T. L. Shek and C. S. M. Ng, "Qualitative evaluation of the Project P.A.T.H.S.: findings based on focus groups with student participants," TheScientificWorldJOURNAL: TSW Child Health \& Human Development, vol. 9, pp. 691-703, 2009.

[40] D. T. L. Shek and C. S. M. Ng, "Secondary 1 program of Project P.A.T.H.S.: process evaluation based on the cowalker scheme," TheScientificWorldJOURNAL: TSW Child Health \& Human Development, vol. 9, pp. 704-714, 2009.

[41] D. T. L. Shek, "Objective outcome evaluation of the Project P.A.T.H.S. in Hong Kong: findings based on individual growth curve models," TheScientificWorldJOURNAL: TSW Child Health \& Human Development, vol. 10, pp. 182-191, 2010.

[42] S. K. M. Tsang, E. K .P. Hui, D. T. L. Shek, and B.C.M. Law, "Subjective outcome evaluation of the Project P.A.T.H.S.: findings based on the perspective of the program implementers (Secondary 1 program)," TheScientificWorldJOURNAL: TSW Child Health \& Human Development, vol. 10, pp. 201-210, 2010.

[43] D. T. L. Shek and R. C. F. Sun, "Effectiveness of the Tier 1 program of Project P.A.T.H.S.: findings based on three years of program implementation," TheScientificWorldJOURNAL: TSW Child Health \& Human Development, vol. 10, pp. 1509-1519, 2010.

[44] D. L. Espelage and S. M. Swearer, "Research on school bullying and victimization: what have we learned and where do we go from here?" School Psychology Review, vol. 32, no. 3, pp. 365-383, 2003.

[45] P. Orpinas and A. M. Horne, Bullying Prevention: Creating a Positive School Climate and Developing Social Competence, American Psychological Association, Washington, DC, USA, 2006. 
[46] R. D. Enright, "The process model of forgiveness," in Dimensions of Forgiveness: Psychological Research \& Theological Perspectives, E. L. Worthington, Ed., pp. 139-164, Templeton Foundation Press, Philadelphia, Pa, USA, 1998.

[47] M. E. McCullough, "Forgiveness: who does it and how do they do it?" Current Directions in Psychological Science, vol. 10, no. 6, pp. 194-197, 2001.

[48] E. L. Worthington, Forgiveness and Reconciliation: Theory and Application, Brunner-Routledge, New York, NY, USA, 2006.

[49] T. W. Baskin and R. D. Enright, "Intervention studies on forgiveness: a meta-analysis," Journal of Counseling and Development, vol. 82, no. 1, pp. 79-90, 2004.

[50] N. G. Wade, E. L. Worthington, and J. E. Meyer, "But do they work? A meta-analysis of group interventions to promote forgiveness," in Handbook of Forgiveness, E. L. Worthington, Ed., pp. 423-439, Brunner-Routledge, New York, NY, USA, 2005.

[51] S. H. Hepp-Dax, Forgiveness as an educational goal with fifth-grade inner-city children, Doctoral dissertation, Fordham University, 1996.

[52] M. E. Gambaro, "School-based forgiveness education in the management of trait anger in early adolescents," Unpublished doctoral dissertation, University of Wisconsin, Madison, Wis, USA, 2002.

[53] S. R. Freedman and R. D. Enright, "Forgiveness as an intervention goal with incest survivors," Journal of Consulting and Clinical Psychology, vol. 64, no. 5, pp. 983-992, 1996.

[54] W. F. Lin, R. D. Enright, D. Krahn, D. Mack, and T. W. Baskin, "Effects of forgiveness therapy on anger, mood, and vulnerability to substance use among inpatient substance-dependent clients," Journal of Consulting and Clinical Psychology, vol. 72, no. 6, pp. 1114-1121, 2004.

[55] E. K. P. Hui and D. K. Y. Ho, "Forgiveness in the context of developmental guidance: implementation and evaluation," British Journal of Guidance and Counselling, vol. 32, no. 4, pp. 477-492, 2004.

[56] E. K. P. Hui and T. S. Chau, "The impact of a forgiveness intervention with Hong Kong Chinese children hurt in interpersonal relationships," British Journal of Guidance and Counselling, vol. 37, no. 2, pp. 141-156, 2009.

[57] E. Ahmed and V. Braithwaite, "Forgiveness, reconciliation, and shame: three key variables in reducing school bullying," Journal of Social Issues, vol. 62, no. 2, pp. 347-370, 2006.

[58] J. Klatt and R. Enright, "Investigating the place of forgiveness within the Positive Youth Development paradigm," Journal of Moral Education, vol. 38, no. 1, pp. 35-52, 2009.

[59] M. Kilpatrick Demaray and C. Kerres Malecki, "A review of the use of social support in anti-bullying programs," Journal of School Violence, vol. 5, no. 3, pp. 51-70, 2006.

[60] J. A. Baker, "Teacher-student interaction in urban at-risk classrooms: differential behavior, relationship quality, and student satisfaction with school," Elementary School Journal, vol. 100, no. 1, pp. 57-70, 2000.

[61] A. Danielsen, O. Samdal, J. Hetland, and B. Wold, “School-related social support and students' perceived life satisfaction," Journal of Educational Research, vol. 102, no. 4, pp. 303-318, 2009.

[62] J. A. Baker, "The social context of school satisfaction among urban, low-income, African-American students," School Psychology Quarterly, vol. 13, no. 1, pp. 25-44, 1998.

[63] R. C. F. Sun and E. K. P. Hui, "Building social support for adolescents with suicidal ideation: implications for school guidance and counselling," British Journal of Guidance and Counselling, vol. 35, no. 3, pp. 299-316, 2007.

[64] E. K. P. Hui and R. C. F. Sun, "Chinese children's perceived school satisfaction: the role of contextual and intrapersonal factors," Educational Psychology, vol. 30, no. 2, pp. 155-172, 2010.

[65] R. S. Atlas and D. J. Pepler, "Observations of bullying in the classroom," Journal of Educational Research, vol. 92, no. 2, pp. 86-99, 1998.

[66] M. Verkuyten and J. Thijs, "School satisfaction of elementary school children: the role of performance, peer relations, ethnicity and gender," Social Indicators Research, vol. 59, no. 2, pp. 203-228, 2002.

[67] G. W. Ladd, B. J. Kochenderfer, and C. C. Coleman, "Friendship quality as a predictor of young children's early school adjustment," Child Development, vol. 67, no. 3, pp. 1103-1118, 1996. 
[68] M. J. Boulton, M. Trueman, S. Bishop et al., "Secondary school pupils' views of their school peer counseling for bullying service," Counselling and Psychotherapy Research, vol. 7, no. 3, pp. 188-195, 2007.

[69] E. K. P. Hui, "A whole-school approach to guidance: Hong Kong teachers' perceptions," British Journal of Guidance and Counselling, vol. 30, no. 1, pp. 63-80, 2002.

\section{This article should be cited as follows:}

Eadaoin K. P. Hui, Sandra K. M. Tsang, and Bella C. M. Law, "Combating School Bullying through Developmental Guidance for Positive Youth Development and Promoting Harmonious School Culture," TheScientificWorldJOURNAL, vol. 11, pp. 2266-2277, 2011. 